\title{
Promoting VET teachers' individual and social learning activities: the empowering and purposeful role of transformational leadership, interdependence, and self-efficacy
}

\author{
Arnoud Oude Groote Beverborg ${ }^{1 *}$, Peter JC Sleegers ${ }^{1}$ and Klaas van Veen ${ }^{2}$
}

\author{
* Correspondence: \\ a.oudegrootebeverborg@utwente.nl \\ 'Department of Educational \\ Science, University of Twente, \\ Enschede, the Netherlands \\ Full list of author information is \\ available at the end of the article
}

\begin{abstract}
Background: This study explores the interaction between organizational and psychological factors that play a role in professional teacher learning. More specifically, how teachers' engagement in learning activities (e.g. keeping up to data, self-reflection, and experimenting, respectively, asking for feedback and information sharing) is influenced by the organizational factors transformational leadership and perceived interdependence, and the psychological factor self-efficacy.

Methods: The study is conducted in the context of Vocational Education and Training (VET) colleges in the Netherlands, using a survey among 447 VET teachers working in 66 teams.

Results: Results showed that self-efficacy and task interdependence directly, and positively, influence a variety of learning activities. Task interdependence influenced self-efficacy positively. Goal interdependence influenced self-efficacy positively, but from the learning activities it only affected information sharing and social reflection positively. From the transformational leadership practices vision building positively affected goal interdependence, and consideration and stimulation positively affected task interdependence.

Conclusions: In general, two configurations for the facilitation of teacher learning were found: one that empowers individual teachers to acquire new knowledge, and another that helps teachers to focus on shared goals and binds them to social learning. Teachers' engagement in learning activities, and consequently VET colleges' change capacities, is optimally facilitated by empowerment and purpose.
\end{abstract}

Keywords: Teamwork; Interdependence; Self-efficacy; Reflective learning activities; Workplace learning; Transformational leadership; Vocational education and training; Structural equation modelling

\section{Background}

This study explores the interaction between organizational and psychological factors that play a role in professional teacher learning in the context of Vocational Education and Training (VET) colleges in the Netherlands. Most studies that explore this interaction have been conducted in primary schools, involved small communities, and thus concerned relatively long and close connections between the teachers with the schools

\section{Springer}

(c) 2015 Oude Groote Beverborg et al.; licensee BioMed Central. This is an Open Access article distributed under the terms of the Creative Commons Attribution License (http://creativecommons.org/licenses/by/4.0), which permits unrestricted use, distribution, and reproduction in any medium, provided the original work is properly credited. 
and also the teachers and students within the schools. VET colleges, in contrast, involve a higher level of education and have gone through many mergers with the formation of massive educational institutions as a consequence. These institutions have attracted experienced professionals from the actual field to teach their students but with a wide variety of experiences and expectations as a consequence - particularly when multidisciplinary teams are formed.

Moreover, this context of VET colleges is interesting because of the current changes in Dutch VET Colleges, which require teachers to collaborate and learn. During the past decade, VET colleges have been confronted with the implementation of so-called Competence-Based Education (CBE). For teachers, CBE means the integration of new theory, practices and subject matter into either existing or new courses (Ritzen, 2004). Teachers from different disciplines and different subjects are called to collaborate for $\mathrm{CBE}$ and thereby instill in students the competences necessary for their future professions. Successful implementation of CBE requires that teachers attune the content of their individual lessons, and that they coordinate to align their collective curriculum. To come to understand how to effectively adjust to such demands, individual and social professional learning activities are deemed necessary (Jarvis, 1987; Smylie, 1995; Stoll et al. 2006; van Woerkom, 2003).

This transition seems to require not only an effort from individual teachers, but also from the organization. To facilitate contact between teachers, they have been organized into interdisciplinary teams (Meirink et al. 2009; Meirink et al. 2010; Poortman, 2007; Truijen, 2012). This ought to facilitate coordination and may also create more potential learning opportunities. However, working in teams does not always accumulate in these desired effects (Meirink et al. 2010; Mueller, et al. 2000; Slavin, 1990). Working in interdisciplinary teams is often foreign to teachers due to the traditionally individualistic nature of the profession. Teachers had been given much autonomy, and they consequently developed a personal responsibility for their classrooms (Somech and Bogler, 2002). Formation of teams in an educational setting is therefore not an easy task and altering the practices of teachers is even more difficult (e.g. Crow and Pounder, 2000; Fullan, 2002; Scribner et al. 2007; Somech and Drach-Zahavy, 2007). The challenge facing these teachers is thus to come to understand how to work effectively together as a team, and take collective responsibility for all students. Adjustment to a policy which requires engagement in both individual and team learning is assumed to be a major hurdle for teachers to overcome today.

To facilitate the transition from more autonomous forms of teaching to teaching in interdisciplinary teams, the building of a school-wide capacity to promote professional learning appears to be a major prerequisite for the successful formation of those teams. The question of how schools can build a capacity to promote teacher professional learning has been addressed in a wide variety of studies concerned with organizational learning, professional learning communities and schools as learning organizations (Bryk et al. 1999; Leithwood and Louis, 1998; Silins et al. 2002; Stoll, 2009). These studies show the beneficial role of teamwork related factors (such as task and goal interdependence, participative decision making, teacher collaboration, and an open and trustful climate) in affecting teacher learning. Additionally, other studies show that teamwork interacts with leadership (such as transformational leadership practices) and psychological factors (such as self-efficacy, experienced autonomy, and individual sense 
making) in fostering professional learning on the part of the teachers (van Veen et al. 2005; Coburn, 2004; Richardson and Placier, 2001; Smylie et al. 1996; Spillane et al. 2002). Especially in the context of teachers required to learn in teams, this interaction between organizational and psychological factors seems to be relevant. The current study extends these findings by placing these factors together in a model that hypothesizes their specific relations, and their effects on a variety of professional learning activities teachers can engage in.

In sum, this study aims to explore how VET teachers' engagement in professional learning activities is influenced by organizational and psychological factors. The following research question guides our inquiry: To what extent do organizational and psychological factors affect teacher learning in VET colleges?

In the next section we provide an overview of the key professional learning activities of teachers and the interplay between organizational factors and psychological factors in teacher learning. To understand their relationships, we draw on theories on adult learning, teacher motivation, teamwork and transformational leadership. Based on these theories and previous research, we will discuss the relationships between specific organizational and psychological factors and teachers' engagement in professional learning activities.

\section{Theoretical context}

The main assumption of this study is that in the context of VET teachers' learning in teams, organizational and psychological factors both play a role in professional teacher learning (cf. Kwakman, 2003; Richardson and Placier, 2001; Smylie et al. 1996). However, as will be argued in this section, each factor is assumed to play a specific role and this study aims to understand the contribution of each factor and the interaction between those factors. Figure 1 summarizes the factors that are taken into account and their assumed relationships.

\section{The interplay between organizational and psychological factors in teacher learning}

The organizational and psychological antecedents to the professional learning and classroom practices of teachers have recently been examined (Geijsel et al. 2009; Thoonen et al. 2011). These studies have shown specific dimensions of the school as a workplace environment (i.e. collaboration, participation, trust) to affect teacher learning but be mediated by such psychological factors as teacher motivation and commitment. Those organizational and psychological factors studied to date have been found to explain only a small to moderate portion of the variance in the professional learning of teachers. It is thus likely that additional organizational and psychological factors may affect teacher learning - particularly when a larger set of professional learning activities is considered than is currently the case. Keeping up to date, experimentation and reflection have been considered in this context, for example, but not social forms of teacher learning such as asking for feedback and sharing of information. Additional research is thus needed to not only validate existing causal models but also expand these models to include additional organizational conditions, psychological factors and professional learning activities for a variety of educational sectors (e.g. secondary education, vocational education, higher education; van Veen et al. 2012). Only with such 


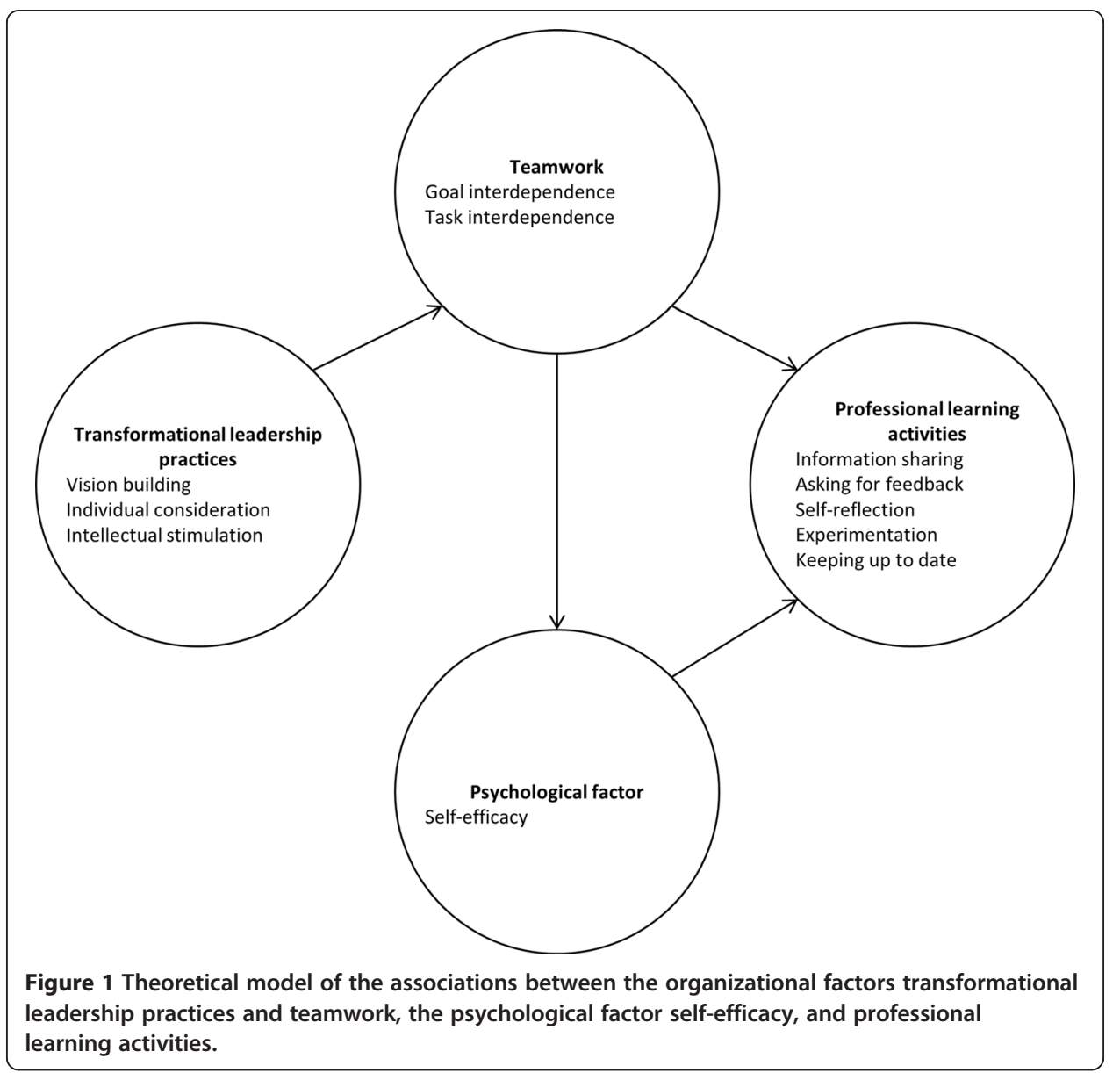

multi-level models can we adequately capture the complexity of education today and yield useful information on the interplay between organizational and psychological factors in teacher learning and the school as a workplace (House et al. 1995).

\section{Engagement in professional learning activities}

Research has shown attendance of professional development workshops and training courses to hardly improve the teaching practices of teachers or help them adapt to changing teaching circumstances (Clarke and Hollingsworth, 2002; Richardson and Placier, 2001). A more promising approach is one in which teachers professionally learn in their workplaces, where their learning is defined as an active, constructive process that is mostly problem oriented, largely grounded in social interaction, and takes place during adulthood (Jarvis, 1987; Marsick and Watkins, 1990; Smylie, 1995). Ongoing, life-long learning is also considered a natural and thus expected component of the professional activities of teachers to improve the quality of instruction and the school itself (Sleegers et al. 2005; Clarke and Hollingsworth, 2002; Cochran-Smith and Lytle, 1999; Desimone, 2009; Jarvis, 1987; Putnam and Borko, 2000; Smylie, 1995).

The focus of teacher learning should thus be on engagement in a variety of professional learning activities within the education context and becoming part of a community of learners (Sfard, 1988; ten Dam and Blom, 2006). Engagement in five core professional 
learning activities can be considered crucial for promoting the professional development of teachers and thereby school improvement (Kwakman, 2003; Lohman and Woolf 2001; Smylie, 1995; van Woerkom, 2004). These five vary from being individual, where others are not necessarily needed, to social learning activities requiring others, though it also can be claimed that the individual forms are more powerful if conducted with others.

The first professional learning activity is keeping up to date (Geijsel et al. 2009; Kwakman, 2003). This includes gaining and maintaining expert knowledge by reading professional literature, and keeping up to date with new developments with regard to teaching, instructional methods, curricula and education in general. Keeping up to date stresses the importance of obtaining new information and insights as part of the individual teacher's professional knowledge base.

The second professional learning activity is experimentation (Kwakman, 2003; van Woerkom, 2003). This refers to efforts to find ways to adapt current teaching practices to changed insights. By experimenting with new approaches and novel methods of instruction, teachers can determine what works in their classrooms. Experimentation is an individual learning activity in which 'knowledge is created by doing'. As much of this knowledge may not be verbal, observation of other teachers' experimentation may be the best way to obtain such knowledge.

The third professional learning activity is self-reflection (Runhaar et al. 2010; van Woerkom, 2003). This refers to a person recreating the experience of acting in a given situation. When insight is gained into the acting, the 'relived' experience can be supplemented with this information to create an altered and thus new experience. This new experience can then serve as the basis for future action (e.g., Barsalou, 2008; Clarke and Hollingsworth, 2002). Self-reflection is thus an individual learning activity aimed at discovering - among other things - a workable script for adaptation to changing circumstances. Although generated by one person, the knowledge gained in such a manner can be made explicit and shared as possibly of value for other individuals and the team, to find solutions to ongoing changes and challenges at work, and to formulate and monitor goals for further development and improvement.

The fourth professional learning activity is asking for feedback (van Woerkom, 2003). This is a social learning activity which resembles, in our view, keeping up to date in that it also entails gathering information (i.e. feedback) but now to identify suitable and not just potential ways of acting. Asking for feedback entails a further commitment to the feedback provided in one way or another (e.g. acceptance or provision of reasons for rejection). Teachers requesting feedback expose themselves to their colleagues, and may thus be accompanied by feelings of uncertainty. Colleagues providing feedback must be explicit for the feedback to be of any use.

The fifth professional learning activity is the sharing of information. This is also a social learning activity and refers to the effort of any team member to keep the flow of information going within a team. Ongoing information sharing means not only making knowledge explicit but also discussing how this information is to be used, and to what purpose. In contrast to asking for feedback, sharing of information is less concerned with something which has come to one teacher's attention for improvement, and more concerned with stimulating all teachers to attend to things that may be improved. Similar to self-reflection, information sharing helps the team in general to monitor its progress (Cochran-Smith and Lytle, 1999; van Woerkom, 2003). 
As such, professional learning activities of teachers can differ with regard to just how the new ideas and practices are generated, where the new ideas and practices come from, who will implement them, and whether they are of an individualistic or social nature (Geijsel et al. 2009; Cochran-Smith and Lytle, 1999; Runhaar, 2008; van Woerkom, 2003). Whereas the individualistic learning activities contribute to the generation of knowledge, engagement in these learning activities make this knowledge only potentially available for others. Through engagement in social learning activities new knowledge becomes available for, and can spread in, the whole team (Stoll et al. 2006). As such, research on just how engagement in social learning, in addition to individualistic learning, can be enhanced by psychological factors such as self-efficacy, and organizational conditions, such as interdependence and leadership, contributes to understanding how effective teams and schools' change capacities can be established.

\section{Teacher learning and self-efficacy}

Amongst the psychological factors that have been found to affect teachers' engagement in professional learning activities, self-efficacy beliefs play an important role (Bandura, 1997; Geijsel et al. 2009). Self-efficacy beliefs refer to the level of competence that a person expects to display in a given situation. Self-efficacy can develop from solving problematic or uncertain situations satisfactorily (i.e., mastery experience) (Bandura, 1997). Teachers with higher levels of self-efficacy challenge themselves to reach more difficult goals, will persist when faced with obstacles, are less constraint by doubt, and will thus arrive more often at satisfying solutions (Bandura, 1993; Caprara et al. 2008; Schwarzer and Hallum, 2008).

When teachers engage in professional learning activities, they run the risk of receiving information which disconfirms their positive self-efficacy beliefs. Such experiences may then limit some teachers while others, who trust in their capacity to resolve problems, will feel competent enough to meet the new challenges; teachers with higher levels of self-efficacy will therefore more easily engage in learning activities. Research has confirmed this positive effect of self-efficacy on professional learning (Moolenaar et al. 2012; Simbula et al. 2011; Yost, 2006). Self-efficacy beliefs can thus motivate teachers to meet challenges and thereby positively influence their engagement in professional learning activities (Geijsel et al. 2009; Thoonen et al. 2011; Runhaar, 2008).

\section{Task and goal interdependence in the facilitation of teacher learning}

Research into schools as professional communities has shown organizational factors such as cooperation, participative decision making and a climate of trust to foster professional learning on the part of teachers (Kwakman, 2003; Leithwood et al. 1999; van Woerkom, 2004). Collaboration and the exchange of knowledge, ideas, and information are further known to lie at the core of professional learning communities (Stoll et al. 2006). Where teaching has traditionally had a high degree of individual autonomy (Clement and Vandenberghe, 2000) - and teachers are thus not accustomed to extensive cooperation and the generation and sharing of knowledge, ideas, and information - working in teams and sharing responsibility to get the work done successfully might overcome this habituation. But little is known about the role of teamwork in the facilitation of teacher learning (Dionne et al. 2004). What we do know is that task and goal 
interdependence can effectively stimulate the members of a team to interact, cooperate and pursue shared goals. Task and goal interdependence can thus facilitate collaboration and thereby both individual and team learning.

\section{Task interdependence}

Task interdependence refers to the degree of interaction between team members and coordination of efforts required to complete a task. For teachers, task interdependence should thus require the exchange of information and resources for successful task completion but also require them to coordinate their actions with those of others (van der Vegt et al. 2000). Task interdependence can thus be seen to provide the infrastructure needed to stimulate teacher interaction and the effective coordination of such interaction (Campion et al. 1993; Cummings, 1978; de Jong et al. 2007). It may thereby facilitate group effectiveness (Truijen, 2012), further collaboration and both social and individual learning (Wageman, 1995). Research on the role of collaboration in the facilitation of teacher learning has indeed revealed direct effects of teacher interaction on the professional learning activities undertaken by teachers as well as indirect effects of collaboration on their learning as mediated by their self-efficacy (Geijsel et al. 2009; Thoonen et al. 2011; Runhaar, 2008; Simbula et al. 2011; Staples and Webster, 2008).

\section{Goal interdependence}

Goal interdependence refers to the degree of coordination and interaction needed for the members of a team to attain both their own goals and the goals of the team (Deutsch, 1980; Weldon and Weingart, 1993). For teachers, goal interdependence thus means that their own costs and benefits depend upon the attainment of not only their own goals but also those of other team members (Runhaar, 2008). Goal interdependence thus requires teachers to pursue a shared goal (van der Vegt and van de Vliert, 2002). This can be the general enhancement of student learning, the creation of an authentic learning environment for students to practice the skills which they will need outside the school setting or - for example - the establishment of competence-based education.

Research has shown goal interdependence to be positively associated with knowledge sharing, open discussion and the exchange of information (Runhaar, 2008; Tjosvold, 1998; Tjosvold et al. 2004a). Additionally, the more teachers have internalized the goals of the school as personal goals, the stronger the belief of the teachers in their capacity to achieve these goals and the greater the degree of engagement of the teachers in professional learning activities (Geijsel et al. 2009; Thoonen et al. 2011; Runhaar, 2008). This makes it likely that an infrastructure that facilitates teachers to be interdependent in goal attainment does not only facilitate teachers' engagement in professional learning activities, but can be expected to also enhance their self-efficacy, that is, the facilitation of teacher learning by goal interdependence can be expected to be mediated by their self-efficacy.

\section{Transformational school leadership}

Transformational leadership is widely assumed to play a major role in the promotion of school improvement efforts and educational change (Leithwood et al. 1999; Leithwood 
and Sleegers, 2006). Transformational school leadership aims to help teachers develop themselves, and foster personal commitment to the organizational goals of a school in order to change the practices of teachers and the school (Leithwood et al. 1999; Ross and Gray, 2006). Research has shown transformational school leadership to correlate with various organizational and teacher conditions (Sun and Leithwood, 2012) including increased participation in decision making and commitment to school improvement as well as increased teacher motivation to implement - for example - accountability policies (Geijsel et al. 2003; Leithwood and Jantzi, 2005; Leithwood et al. 2002). The findings regarding the influence of transformational leadership on teacher learning have not been consistent, however. The impact has been sometimes positive, sometimes negative and sometimes absent (Geijsel et al. 2009; Thoonen et al. 2011; Runhaar, 2008).

Three dimensions of transformational leadership have been identified as critical for the facilitation of teacher learning: 1) identifying and articulating a vision which fosters the development of shared goals and priorities; 2) attention to individual needs and feelings; and 3) intellectual stimulation with sufficient challenge and support (Geijsel et al. 1999; Geijsel et al. 2009; Nguni et al. 2006; Thoonen et al. 2011; Leithwood and Jantzi, 2006; Leithwood et al. 1999). In addition to these insights, it has recently been shown that transformational school leadership can enhance the prerequisites for effective teamwork - including teacher participation in decision making, teacher collaboration and trust (Moolenaar et al. 2012; Thoonen et al. 2011). A conceptual link can thus be drawn between the three key dimensions of transformational leadership and the promotion of teamwork in a school.

With the articulation of a shared vision or the first dimension of transformational leadership identified as critical for teacher learning, the transformational school leader inspires teachers to formulate shared goals, connect to these, commit to them and try to attain them with increased teacher cooperation as a result (Thoonen et al. 2011). With this increasingly collective effort, individual teachers may then gain greater confidence in their ability to realize both their own goals and those of the school (Geijsel et al. 2003).

Individual support and attention are needed as part of transformational school leadership because this requires school leaders to recognize, understand and meet the needs and concerns of team members. Transformational school leaders should also act as role models, delegate challenging tasks, offer feedback and provide coaching in order to help individual teachers reach their personal potential. Teachers should feel empowered by a supportive, transformational school leader and - as a consequence - seek to interact with other teachers and coordinate responsibility in the tasks they share (Dionne et al. 2004; Geijsel et al. 2009).

Intellectual stimulation or the third dimension of transformational leadership critical for the enhancement of teacher learning involves the encouragement of teachers to continually question their beliefs, assumptions and values. It tries to incite a critical attitude towards oneself and one's team members, that there are alternative solutions for the same problems, and that conflict can be functional for effective teamwork. As such, it can improve teamwork by enhancing teachers' abilities to solve individual, group and organizational problems (Dionne et al. 2004; Geijsel et al. 2009).

In sum, it is likely that transformational leaders can have a modest, indirect impact on the engagement of teachers in professional learning activities if sufficiently supportive workplace conditions are provided and teachers have a strong sense of self-efficacy. 


\section{The present study}

The aim of the present study is to examine the impact transformational leadership, teamwork, and self-efficacy, have on teacher learning in VET colleges. The conceptual model of the study that summarizes the various paths via which teachers' engagement in professional learning activities can be influenced was already presented in Figure 1. Based on previous studies, we hypothesize that self-efficacy positively affects teachers' engagement in professional learning activities (hypothesis 1). With regard to the impact teamwork processes may have on teacher engagement in professional learning activities, we hypothesize that perceived task and goal interdependence will affect teachers' engagement in learning activities positively (hypothesis 2) and that the effect of perceived task and goal interdependence on teachers' engagement in professional learning activities will be mediated by teachers' sense of self-efficacy (hypothesis 3). Regarding the impact of transformational leadership practices (e.g., vision building, individualized support and intellectual stimulation) on teacher engagement in professional learning activities, we expect that transformational leadership indirectly fosters the engagement of teachers in professional learning activities with perceived goal and task interdependence mediating the effects (hypothesis 4).

\section{Method}

\section{Context, data collection, and sample}

The data collection for this study was conducted in interdisciplinary teams of six Vocational Education and Training colleges in the Netherlands in 2010. VET colleges have four levels, which represent a certain amount of mastery of an occupation. Students who have successfully finished the fourth level have, ideally, acquired all knowledge and skills to practice their profession fully and independently. People of any age (but at least 15 years old) may enroll to learn a (new) occupation.

Interdisciplinary teams consist of teachers who have complementary specializations needed to teach students their future professions. Some of those teachers have been educated as teachers themselves (and have at least a bachelor's degree), and some teachers have gained much experience in the professional field (and may have any degree). The interdisciplinary teams were responsible for the coaching of a specific group of students, the guidance of their learning processes, the planning of the curricula for the group and assessment of their progress. Each team of teachers is responsible for the education of students for a profession in areas such as laboratory technology, electro technology, media technology, ICT, engineering, automobile technology, transport, tourism, catering industry, bakery and pastry, retail trade, business administration, law, and so on.

We used convenience sampling to obtain a sample as large as possible. The VET colleges were contacted via their board of directors. To increase the response, we provided the teacher teams information about the aim of study, the content of the questionnaire and offered them a presentation of the main findings in four of the six VET colleges. This strategy resulted in a total of 30 teams (7 or 8 per college) that were willing to participate. In the other two colleges, teachers were asked directly to participate in the study by email. This strategy resulted in a total of 37 teams (23, respectively 14, per college).

The questionnaires were administered through the online program survey-monkey. Questionnaires were sent to 853 teachers of 67 teams. In one VET college 14 teachers 
were not part of a team, and were excluded from further analysis. Moreover, teachers from one team did not respond, resulting in an effective amount of 66 teams for further analysis. A total of 447 teachers completed the questionnaire (total response rate: 52\%). Response rates of the two VET colleges whose teachers were contacted directly (by email) showed to be considerably lower (30 percent, respectively 50, percent), than those of the VET colleges whose teams were asked through their team leaders (all above 70\%).

These differences, and especially the low response rates in some of the teams, hindered a comparison between teams. Moreover, the teams differed in size: the smallest team held 4 teachers, and the largest team held 25 teachers.

Of all the teachers who responded, $67 \%$ was male. The average age of the respondents was 48 years (standard deviation of 9 , minimum of 22, maximum of 62). The majority of the respondents worked more than 32 hours per week (61\%). Many of the respondents had worked as a teacher for more than 20 years (33\%); a sizeable percentage had worked around 10 years as a teacher (20\%); and a small percentage had just begun working as a teacher (4\%). Most of the teachers had a bachelor's degree (72\%); $16 \%$ had a master's degree; and $12 \%$ had completed only a secondary level of education.

\section{Measures of the model variables}

As we aimed to explore how transformational leadership practices, perceived task and goal interdependence, teachers' self-efficacy beliefs affect teachers' their engagement in professional learning activities within the context of VET colleges and how these findings are related to findings of previous cross-sectional studies into teacher learning in primary education, we chose a survey design. The variables examined in our study were assessed using already existing, well-validated measurement scales: transformational leadership vision building, individual consideration and intellectual stimulation (Geijsel et al. 2009; see also Geijsel et al. 2001; Leithwood et al. 1993; Silins, 1994); perceived task and goal interdependence (Runhaar, 2008; van der Vegt et al. 2000); job self-efficacy (Runhaar, 2008; Schyns and Von Collani, 2002); keeping up to date (Geijsel et al. 2001; Geijsel et al. 2009); and teacher reflection (Runhaar, 2008; van Woerkom, 2003).

In addition, experimentation was measured using two items selected from the experimentation and reflective-action scale developed by Geijsel et al. (2009) and two newly formulated items. Asking for feedback and information sharing were measured using items from the knowledge-sharing and feedback-asking scales developed by van Woerkom (2003) together with two items selected from a validated experimentation and reflectiveaction scale (Geijsel et al. 2009).

All questionnaire items were responded to along a 5-point Likert scale $(1=$ disagree much, $2=$ disagree, $3=$ do not disagree, do not agree, $4=$ partially agree, $5=$ agree much.

Our questionnaire initially contained 56 questions distributed across 11 scales. Preliminary exploratory factor analysis, (with oblimin rotation and maximum likelihood extraction; using SPSS 20) revealed only two as opposed to three transformational leadership variables (i.e. vision building and the combination of intellectual stimulation with individual support) and only four on stead of five professional learning activities (i.e. keeping up to date, experimentation, self-reflection and the scale called information 
sharing and social reflection'). The combination of individualized consideration and intellectual stimulation, but not vision building, suggests that teachers distinguish between leadership practices that address the whole team versus those that address them individually, but that they do not distinguish in whether they are individually empowered or individually challenged. The combination of asking for feedback and information sharing suggest that teachers do not distinguish in the direction information travels in, and consequently in whether they receive or provide information. Based on these findings, the number of items was reduced to 50 and the number of factors reduced to 9 .

To see if the theoretical constructs (factors) such as we measured them fitted well to the data in relation with one another, a measurement model was next created using Mplus7 (Muthén and Muthén, 1998-2012). The findings showed a sufficient fit of the model to the actual data, $\mathrm{X}^{2}(1139)=2643.266, \mathrm{p}=.000, \mathrm{RMSEA}=0.054, \mathrm{CFI}=0.889$, SRMR $=0.051$. The scales were found to show good reliability (Cronbach's $\alpha$ 's ranged from .718 to .956). The parameter estimates (i.e. factor loadings and residual variances), as well as the $\alpha$ 's for each scale, are presented in Additional file 1: Appendix A. In order to conduct multilevel analysis, we needed to reduce the number of parameters in the model. On the basis of the findings from the measurement model, we therefore constructed scales by averaging the item scores. For the means, standard errors, and correlations between the scales, see Additional file 1: Appendix B.

\section{Analysis-procedure for the structural model}

The relationships between the variables depicted in Figure 1 were investigated through multilevel structural equation modeling (MSEM), using the computer program Mplus7 (Muthén and Muthén, 1998-2012). Given the nested structure of our sample (teachers nested within teams), and the possible dependence between teachers within teams that may result, we computed, the intraclass correlations (ICC's). ICC is the proportion of the total variance that is explained by group membership. Larger ICC's indicate that respondents are more alike (Bliese, 2000). ICC values of .10 are considered as medium, and those of .15 as large, in educational contexts (Hox, 2002, page 184). Five variables had ICC's larger than .10, see Additional file 1: Appendix B. Ignoring the nested structure of the data would therefore lead to underestimated of the standard errors, which would lead to a higher type I error rate (i.e., finding a parameter significant when it is actually zero in the population). Given the fact that our variables were all assessed at the individual level and the fact that the study focused on important regression parameters (fixed effects) and not on school- or team-level variance (random effects), we decided to perform further analyses on the within-school covariance matrix by means of testing the "complex structure" in Mplus (Muthén and Muthén, 1998-2012). This option separates the team level from the individual level variance in which we are interested, and allows for modelling of the individual level, while taking the nested nature of the data into account. It gives maximum likelihood estimates with robust standard errors and a robust chi-square $\left(\mathrm{X}^{2}\right)$ measure of overall goodness of fit (Yuan and Bentler, 2000). In addition, the associated Root Mean Square Error of Approximation (RMSEA), the Comparative Fit Index (CFI, Hu and Bentler, 1999) and the Standardized Root mean Square Residual (SRMR) were calculated. The fit of the model was found to be 
good when $\mathrm{X}^{2}$ is not significant, the SRMR $\leq .08$, the RMSEA $\leq .06$ and the CFI $\geq .95$ (Hu and Bentler, 1999; see also Kenny, 2012).

We compared nested models using the Satorra-Bentler scaled chi-square difference test $\left(\Delta \mathrm{X}_{\mathrm{SB}}^{2}\right.$, Satorra and Bentler, 2001) with degrees of freedom (df) equal to the difference in the numbers of parameters left free for estimation. When appropriate, model modifications were made on the basis of the standardized residuals and modification indices. Effect sizes were judged to be small at .05 , moderate at .15 or large at .35 (Field, 2009).

\section{Results}

The structural path model as specified by our hypotheses (see also Figure 1) was fit to the data. The fit of this model (model 1) to the data was good as indicated by a RMSEA of .041 , a CFI of .989, an SRMR of .033, and a $\mathrm{X}^{2}(10)$ of $17.682(\mathrm{p}=.061)$. One possible association to be added to the model was indicated by the modification index: This was the reversed effect of information sharing and social reflection on goal interdependence. We did not add this association to the model, but the finding indicates the possibility of a reciprocal relation between goal interdependence and social learning and is therefore worthy of further exploration in the future. In keeping with the principal of parsimony, we removed all non-significant effects from the model. These were the effect of vision building on task interdependence, and the effect of consideration and stimulation on goal interdependence, as well as the effects of goal interdependence on self-reflection, experimentation, and keeping up to date. This resulted in a model with a good fit, RMSEA $=.027, \mathrm{SRMR}=.035, \mathrm{CFI}=0.993$ and $\mathrm{X}^{2}(15)=19.873(\mathrm{p}=.177)$. The more parsimonious model (model 2) fitted just as well as the first model, $\Delta \mathrm{X}_{\mathrm{SB}}^{2}(5)=2.362, \mathrm{p}=.797$. The effect sizes are included in Figure 2. Direct, indirect and total effects are reported in Table 1.

The final structural modeling results show leadership practices, perceived goal and task interdependence and self-efficacy to jointly explain a significant amount of the variation in the engagement of VET teachers in professional learning activities: $33.6 \%$ of the variation in information sharing and social reflection; $16.3 \%$ for experimentation; 23.8\% for self-reflection; and 9.0\% for keeping up to date.

A closer look at the effects showed - in keeping with what we hypothesized - teacher engagement in the four professional learning activities to be directly influenced by selfefficacy (hypothesis 1). When teachers show stronger beliefs in their capacity to achieve a desired result, they also show greater engagement in professional learning activities. The significant effects of self-efficacy on information sharing and social reflection, selfreflection, experimentation, and keeping up to date were moderate to strong with values of .31, .32, .33 and .27, respectively.

Task interdependence was also found to directly affect teacher engagement in all four types of professional learning activity (hypothesis 2). The more teachers perceive a need to exchange information and resources with other team members to successfully complete tasks, the more they engage in professional learning. While all of the effects of task interdependence were moderate (i.e., .34 for knowledge sharing and social reflection, .27 for reflection, .20 for experimentation, .16 for keeping up to date), the effect of task interdependence on knowledge sharing and social reflection was double the size of the effect on keeping up to date. The results further showed a moderate effect (.29) of task interdependence on individual self-efficacy, which is in keeping with our 


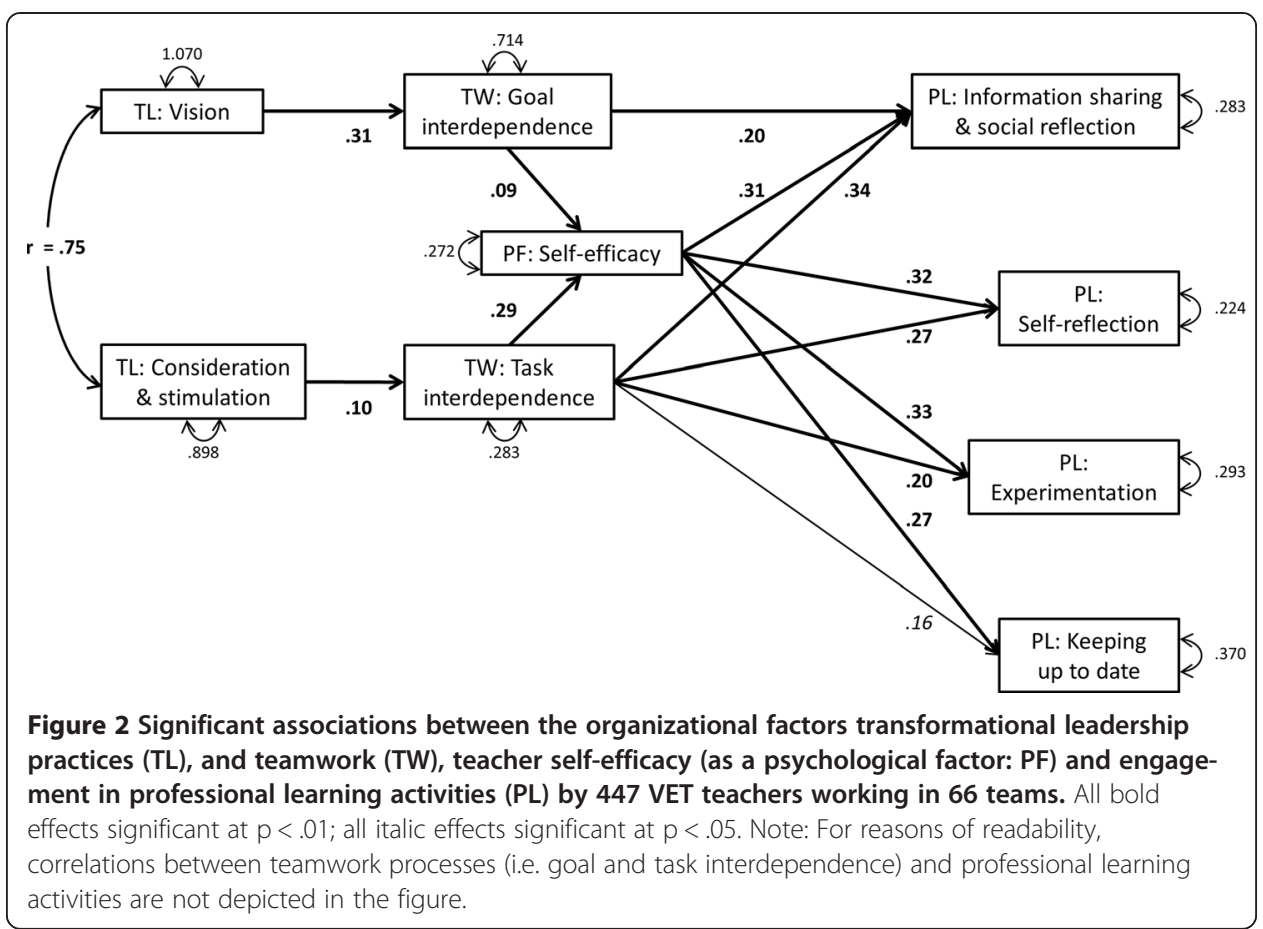

hypothesis 3 . Teachers who see themselves more as having to work together to successfully complete tasks also believe more in their capacity to perform effectively (i.e., greater self-efficacy is associated with greater task interdependence).

The effects of goal interdependence on teacher engagement in professional learning activities proved different than expected (hypothesis 2). Only a moderate effect (.20) on information sharing and social reflection was found. Teachers who report working on a

Table 1 Direct, indirect and total effects of TL practices, teamwork, and self-efficacy on learning activities

\begin{tabular}{|c|c|c|c|c|c|}
\hline & & $\begin{array}{l}\text { Information sharing } \\
\text { \& social reflection }\end{array}$ & Self- reflection & Experimentation & $\begin{array}{l}\text { Keeping up } \\
\text { to date }\end{array}$ \\
\hline \multirow[t]{3}{*}{ TL: vision } & direct & $x$ & $x$ & $x$ & $x$ \\
\hline & indirect & 0,07 & 0,01 & 0,01 & 0,01 \\
\hline & TOTAL & 0,07 & 0,01 & 0,01 & 0,01 \\
\hline \multirow{3}{*}{$\begin{array}{l}\text { TL: consideration } \\
\text { \& stimulation }\end{array}$} & direct & $x$ & $x$ & $x$ & $x$ \\
\hline & indirect & 0,04 & 0,04 & 0,03 & 0,02 \\
\hline & TOTAL & 0,04 & 0,04 & 0,03 & 0,02 \\
\hline \multirow[t]{3}{*}{ Task interdependence } & direct & 0,34 & 0,27 & 0,20 & 0,16 \\
\hline & indirect & 0,09 & 0,09 & 0,10 & 0,08 \\
\hline & TOTAL & 0,43 & 0,36 & 0,30 & 0,24 \\
\hline \multirow[t]{3}{*}{ Goal interdependence } & direct & 0,20 & $x$ & $x$ & $x$ \\
\hline & indirect & 0,03 & 0,03 & 0,03 & 0,02 \\
\hline & TOTAL & 0,23 & 0,03 & 0,03 & 0,02 \\
\hline \multirow[t]{3}{*}{ Self-efficacy } & direct & 0,31 & 0,32 & 0,33 & 0,27 \\
\hline & indirect & $x$ & $x$ & $x$ & $x$ \\
\hline & TOTAL & 0,31 & 0,32 & 0,33 & 0,27 \\
\hline
\end{tabular}

$\mathrm{TL}=$ Transformational Leadership. 
shared goal more are also more engaged in sharing of information, discussion and seeking of advice. As expected (hypothesis 3), goal interdependence exerted a small (.09) but nevertheless significant effect on the individual self-efficacy of the teachers responding in our study. Those teachers who perceive more goal interdependence also report higher levels of self-efficacy. This effect was less strong than the effects of task interdependence on the individual self-efficacy of the teachers (see Figure 2).

We found the two transformational leadership practices to significantly influence the engagement of teachers in professional development activities but differently than expected (hypothesis 4). On the one hand, consideration and stimulation exerted a small effect on task interdependence (.10), as expected, but not on goal interdependence, which was counter to what we expected. On the other hand, vision showed a moderate effect on goal interdependence (.31), as expected, but not on task interdependence. These findings show different leadership practices to have a differential impact on teamwork processes. Teacher perceptions of working together towards a shared goal are facilitated by leaders working to create a shared vision, shared goals, and shared priorities. Teacher perceptions of working together to complete tasks are facilitated by leaders who provide individual support and intellectual stimulation to teachers. Consequently, vision building had its indirect effect mostly on the learning activity information sharing and social reflection, whereas consideration and stimulation had its indirect effects on all learning activities distributed more evenly (Table 1).

\section{Discussion}

We formulated and tested a model that was previously assessed in primary education, and selected organizational and psychological factors that were shown to affect Vocational Education and Training teachers' engagement in professional learning activities. More specifically, we assessed how transformational leadership practices, perceptions of interdependence and self-efficacy beliefs can facilitate teacher engagement in both individual and social professional learning activities, using a sample of 447 Dutch VET teachers working in 66 teams in 6 VET colleges.

Results from the factor analyses showed one instead of two social learning activities. Apparently, teachers do not distinguish between asking for feedback and information sharing, but tend to perceive it as one, social, learning activity. Although asking feedback and sharing information are often distinguished as two analytic different learning activities in the literature, our findings indicate that VET teachers do not consider these as separate activities in their daily practice. This may suggest that most interaction between VET teachers is strongly reciprocal in nature: while collaborating, teachers are simultaneously engaged in sharing information and asking feedback. To more fully understand the process of social learning, future research could assess whether different social learning activities may be related to environmental factors such as learning climate and trust, or rather to more personal factors such as uncertainty, expertise, or task demands (e.g., Little, 1990; Spillane et al. 2012). Additionally, factor analysis on the transformational leadership dimensions showed two instead of three dimensions. Apparently, teachers do not distinguish between leadership practices directed at attending and supporting their needs, and practices that are meant to stimulate teachers intellectually and encourage them to question their beliefs, assumptions, and values. This may 
indicate that teachers perceive these practices as efforts to empower them to and improve their teaching (c.f., Jung and Sosik, 2002).

The findings from the parsimonious structural model showed high effects of teacher self-efficacy on engagement in all four categories of professional learning activities. This finding confirms the importance of self-efficacy for teacher learning, as found in previous studies (Geijsel et al. 2009; Thoonen et al. 2011; Bandura, 1993; Simbula et al. 2011; Yost, 2006),

With respect to the role of teamwork in teachers' engagement in professional development activities, task and goal interdependence were found to have differential effects - which was counter to what we hypothesized. Our data shows perceived task interdependence to clearly affect the learning of teachers in VET colleges. Organizing teachers to be interdependent for task performance thus appears to stimulate them to engage in a variety of learning activities which include making knowledge explicit, the sharing of information and the gathering of new information.

Our data further shows perceived goal interdependence to only affect the learning activity of information sharing and social reflection. That is, teachers working towards a shared goal appear to have better interpersonal communication but not necessarily greater personal reflection, independent acquisition of knowledge from external sources or modification of current teaching methods.

Although both task and goal interdependence facilitate teacher interactions, they differ in purpose. Task interdependence refers to interaction between team members required to complete their tasks successfully, while goal interdependence facilitates interaction needed to reach a team's common goal. Given that teachers teach their classes mostly individually, the interdependence they perceive in tasks mostly refers to the content they provide their students in their lessons. Task interdependence therefore seems to drive any activity to improve individual teachers' instruction by means of collecting and generating new knowledge and skills. Perceptions of goal interdependence on the other hand refer to the mutual pursuit of a team's common goal. It stimulates identification with the team, mobilizes interpersonal relationships, and offers opportunities to exchange ideas, and explore and understand mutual perspectives in order to achieve the team's aims. Goal interdependence seems therefore specifically directed at coordinating and discussing shared team goals, whereas task interdependence seems generally directed at the generation of knowledge for the improvement of individual teacher's classroom practices. Thus, the difference in purpose of task and goal interdependence (c.f. van der Vegt and van de Vliert, 2002), may explain the differential effect of task and goal interdependence on teachers' engagement in social and individual learning activities.

Given the different role task and goal interdependence play in explaining teacher learning, the findings also show that the influences of both are mediated - as we hypothesized - by the teacher's sense of self-efficacy. These findings thus confirm the importance of considering individual psychological factors in connection with teacher learning and underline the need for more research on the interplay between psychological and teamwork processes (e.g., Staples and Webster, 2008).

With regard to school leadership, vision building showed a strong, direct effect on goal interdependence but not task interdependence. This supports the claim that with the formulation of a clear and shared vision, the transformational school leader can 
inspire teachers to formulate, identify with, commit to and strive to realize shared goals (Thoonen et al. 2011). In contrast to vision building, individual consideration and intellectual stimulation from the school leader showed only a - direct - effect on task interdependence. When school leaders attend more to the needs and feelings of teachers, and teachers are also challenged more by school leaders to explore new things, seek new methods and reflect on existing practices, teachers are inclined to perceive a stronger need to work together. This finding shows leadership practices to clearly empower teachers and encourage them to engage in variety of professional learning activities (Dionne et al. 2004; Tjosvold et al. 2004b).

\section{Limitations of the present study}

The present study found that self-efficacy and task interdependence directly, and positively, influence a variety of learning activities (at least all included in this study), and that task interdependence influences self-efficacy positively as well. Goal interdependence also influenced self-efficacy positively, but from the learning activities it only affected information sharing and social reflection (positively). From the transformational leadership practices vision building positively affected goal interdependence, and consideration and stimulation positively affected task interdependence.

The model tested here obviously simplifies what actually happens in a vocational teaching context. Teaching occurs, by definition, in a complex environment with numerous factors interacting at numerous levels not included in the current model (House et al. 1995). The model might therefore be expanded to include - among other things - distributed forms of leadership (Spillane et al. 2002), emotions such as anxiety and uncertainty (van Veen et al. 2005), the role of conflict in teacher engagement (Johnson and Johnson, 2009) and identification with the team (or not) (van Veelen et al. 2013). Future research may also assess the role different learning activities play in changing teaching practices and elevating student results (Thoonen et al. 2011).

Additionally, measurement instruments and the formulation of items in surveys should be situation specific. Consequently, we used measures that tapped into general workplace circumstances (e.g., job self-efficacy). However, the findings from the current study might be validated with measures that are more adjusted to the teacher profession, such as teacher self-efficacy (Schwarzer et al. 1999).

The role of team-level factors might also be examined at the level of the team in addition to the individual level, by using multilevel analysis techniques that model variables that are conceptually relevant at the team level (e.g. Preacher et al. 2010; Truijen, 2012), such as team leadership, and team learning (Yammarino et al. 2008). Such models may also include team measures such as the degree of diversity and longevity (Schippers et al. 2003), collective efficacy (Moolenaar et al. 2012), shared mental models (Tjosvold et al. 2004b) or and other variables needed to create multilevel models.

In future research, the beneficial effects teacher learning has on both their teaching practices and student performance should also be considered. Finally, longitudinal research is needed to ascertain the direction of causality for the associations identified in the present research (Heck and Hallinger, 2010). We can ask, for example, whether greater teacher engagement in professional learning activities over time is caused by 
steady states or concomitant growth in leadership practices, improvement of teamwork and enhanced self-efficacy (Sleegers et al. 2014). Longitudinal research also provides opportunities to examine how the relationships between the variables we examined in our study are mutually shaped over time.

\section{Conclusion}

In conclusion, our context specific findings (Edmondson et al. 2007) indicate two different paths that link transformational leadership practices, goal and task interdependence as an infrastructure for peer interaction, teachers' beliefs about their self-efficacy, and, consequently, their engagement in professional learning activities. The first path to explain the variation in teachers' engagement in professional learning activities leads from a school leader who attends the needs and feelings of individual teachers and challenges them intellectually, to teachers working together to complete tasks and having a positive sense of self-efficacy, to teachers' engagement in professional learning activities. With personal attention from the school leader acting as a positive role model, teachers tend to be more motivated to collaborate with their team members, believe more in their capacity to overcome problems and - as a result - are more engaged in individual learning activities such as self-reflection, and keeping up to date. This link between the variables examined indicates how teachers can be empowered to become engaged in individual learning activities aimed at generating new knowledge. As a multifaceted approach to teacher empowerment, the findings suggest that transformational leadership and team interaction can help teachers to cope with individual solutions for ongoing changes.

The second path links a leader who shares a vision, to teacher perceptions of being goal interdependent, to teachers sharing information and engaging in social reflection. These links indicate how school leaders can provide shared focus that binds teachers together. With the clear formulation and sharing of the school's mission (i.e., vision), transformational school leaders can encourage teachers to formulate and share related team goals and to work together to achieve these goals. The teachers may subsequently ask each other for advice and monitor their collective progress towards the achievement of these goals. Sharing information and social reflection are thus situated within the context of achieving shared goals and thus cultivated when the school leader continues to articulate and share the school's mission.

We therefore agree with pleas that teacher development research should focus on specific school leadership practices rather than the effects of the school leadership as a whole (Leithwood et al. 2008; Thoonen et al. 2011). To effectively steer towards improved teacher learning in schools, school leaders can engage in supportive and stimulating practices, given the right infrastructure for collaboration. Free from barriers, and supported by structural resources, teachers will be motivated and become empowered to engage in learning activities that can generate new knowledge. When a school leader is particularly interested in elevating the exchange of knowledge and information amongst teachers, vision building practices and an environment that necessitates shared goals as an organic norm (Rowan, 1990) contribute additional to influences aimed at stimulating empowerment. Supplying content and purpose seem especially strong to overcome the persistence of privacy (Little, 1990) and enhance the change capacity of schools to implement educational reforms such as competence-based education. 


\section{Additional file}

Additional file 1: Appendices.

\section{Competing interests}

The authors declare that they have no competing interests.

\section{Authors' contributions}

AOGB collected the data, conducted the analyses, wrote the first draft and processed changes to the manuscript. PS conceived of the study, participated in its design, helped to draft the manuscript, and suggested and made improvements to the manuscript. KvV co-conceived of the study and finalized the manuscript. All authors read and approved the final manuscript.

\section{Acknowledgements}

This work was supported by the NWO Programming Council for Educational Research (PROO) [grant number 411-07-302]. We thank Lee Ann Weeks for improving the manuscript's style and language.

\section{Author details}

${ }^{1}$ Department of Educational Science, University of Twente, Enschede, the Netherlands. ${ }^{2}$ Teacher Education, University of Groningen, the Netherlands.

Received: 28 October 2014 Accepted: 24 February 2015

Published online: 22 March 2015

\section{References}

Bandura A (1993) Perceived self-efficacy in cognitive development and functioning. Educ Psychol 28:117-148 Bandura A (1997) Self-efficacy: the exercise of control. Freeman, New York Barsalou LW (2008) Grounded cognition. Annu Rev Psychol 59:617-645

Bliese PD (2000) Within-group agreement, non-independence, and reliability: Implications for data aggregation and analysis. In: Klein KJ, Kozlowski SW (eds) Multilevel Theory, Research, and Methods in Organizations: Foundations, Extensions, and New Directions. Jossey-Bass Inc., San Francisco, pp 349-381

Bryk A, Camburn E, Louis KS (1999) Professional community in Chicago elementary schools: facilitating factors and organizational consequences. Educ Admin Quart 35:751-781

Campion MA, Medsker GJ, Higgs AC (1993) Relations between work groups characteristics and effectiveness: implications for designing effective work groups. Pers Psychol 46(4):823-847

Caprara GV, Fida R, Vecchione M, Del Bove G, Vecchio GV, Barbaranelli C, Bandura A (2008) Longitudinal analysis of the role of perceived self-efficacy for self-regulated learning in academic continuance and achievement. J Educ Psychol 100(3):525-534

Clarke DJ, Hollingsworth H (2002) Elaborating a model of teacher professional growth. Teach Teach Educ 18:947-967

Clement M, Vandenberghe R (2000) Teachers' professional development: a solitary or collegial (ad)venture? Teach Teach Educ 16:81-101

Coburn CE (2004) Beyond decoupling: rethinking the relationship between the institutional environment and the classroom. Sociol Educ 77:211-244

Cochran-Smith M, Lytle SL (1999) Relationships of knowledge and practice: teacher learning in communities. Rev Res Educ 24:249-305

Crow GM, Pounder DG (2000) Interdisciplinary teacher teams: context, design, and process. Educ Admin Quart 36 (2):216-254

Cummings TG (1978) Self-regulating work groups: a socio-technical analysis. Acad Manage Rev 3:625-634

de Jong SB, van der Vegt GS, Molleman E (2007) The relationships among asymmetry in task dependence, perceived helping behavior, and trust. J Appl Psychol 92(6):1625-1637

Desimone LM (2009) Improving impact studies of teachers' professional development: toward better conceptualizations and measures. Educ Res 38(3):181-199

Deutsch M (1980) Fifty years of conflict. In: Festinger L (ed) Retrospections on social psychology. Oxford University Press, New York, pp 46-77

Dionne SD, Yammarino FJ, Atwater LE, Spangler WD (2004) Transformational leadership and team performance. J Organ Change Manag 17:177-193

Edmondson AC, Dillon JR, Roloff KS (2007) 6 Three perspectives on team learning: outcome improvement, task mastery, and group process. Acad Manag Ann 1(1):269-314

Field A (2009) Discovering statistics using SPSS. Sage Publications, Ltd, London

Fullan M (2002) The change leader. Educ Leadership May:16-21

Geijsel FP, Sleegers PJC, van den Berg RM (1999) Transformational leadership and the implementation of large-scale innovation programs. J Educ Admin 37:309-328

Geijsel F, Sleegers P, van den Berg R, Kelchtermans G (2001) Conditions fostering the implementation of large-scale innovation programs in schools: Teachers' perspectives. Educ Admin Quart 37:130-166

Geijsel F, Sleegers P, Leithwood K, Jantzi D (2003) Transformational leadership effects on teachers' commitment and effort toward school reform. J Educ Admin 41:229-256

Geijsel FP, Sleegers PJC, Stoel RD, Kruger ML (2009) The effect of teacher psychological and school organizational and leadership factors on teachers' professional learning in Dutch schools. Elem School J 109(4):1-22

Heck RH, Hallinger P (2010) Collaborative leadership effects on school improvement: Integrating unidirectional-and reciprocal-effects models. Elem Sch J 111(2):226-252 
House R, Rousseau DM, Thomas-Hunt M (1995) The meso paradigm: a framework for the integration of micro and macro organizational behavior. Res Organ Behav 17:71-114

Hox JJ (2002) Multilevel analysis: Techniques and applications. Lawrence Erlbaum Associates, Mahwah, NJ

Hu L, Bentler PM (1999) Cutoff criteria for fit indexes in covariance structure analysis: conventional criteria versus new alternatives. Struct Equ Model 6:1-55

Jarvis P (1987) Adult learning in the social context. Croom Helm, London

Johnson DW, Johnson RT (2009) Energizing learning: the instructional power of conflict. Educ Res 38(1):37-51

Jung DI, Sosik JJ (2002) Transformational leadership in work groups the role of empowerment, cohesiveness, and collective-efficacy on perceived group performance. Small Group Res 33(3):313-336

Kenny DA (2012) Measuring model fit. http://davidakenny.net/cm/fit.htm. Accessed 4 September 2012

Kwakman K (2003) Factors affecting teachers' participation in professional learning activities. Teach Teach Educ 19:149-170

Leithwood K, Jantzi D (2005) A review of transformational leadership research 1996-2005. Leadersh Policy Sch 4(3):177-200

Leithwood K, Jantzi D (2006) Transformational school leadership for large-scale reform: effects on students, teachers, and their classroom practices. Sch Eff Sch Improv 17:201-227

Leithwood K, Louis KS (eds) (1998) Organizational learning in schools. Swets and Zeitlinger, Lisse

Leithwood K, Sleegers P (Eds) (2006) Special Issue of Sch Eff Sch Improv. Transformational School Leadership 17(2)

Leithwood K, Dart B, Jantzi D, Steinbach R (1993) Building commitment for change and fostering organizational learning (Final report for phase 4 of the Implementing British Columbia's Education Policy research project). British Columbia Ministry of Education, Victoria

Leithwood K, Jantzi D, Steinbach R (1999) Changing leadership for changing times. Open University Press, Buckingham

Leithwood K, Steinbach R, Jantzi D (2002) School leadership and teachers' motivation to implement accountability policies. Educ Admin Quart 38(1):94-119

Leithwood K, Harris A, Hopkins D (2008) Seven strong claims about successful school leadership. School Leadership Manage 28(1):27-42

Little J (1990) The persistence of privacy: autonomy and initiative in teachers' professional relations. Teach Coll Rec 91 (4):509-536

Lohman MC, Woolf NH (2001) Self-initiated learning activities of experienced public school teachers: methods, sources, and relevant organizational influences. Teachers Teach 7:59-74

Marsick VJ, Watkins K (1990) Informal and incidental learning in the workplace. Routledge, London

Meirink JA, Meijer PC, Verloop N, Bergen TC (2009) How do teachers learn in the workplace? An examination of teacher learning activities. Eur J Teach Educ 32(3):209-224

Meirink JA, Imants J, Meijer PC, Verloop N (2010) Teacher learning and collaboration in innovative teams. Cambridge J Educ 40(2):161-181

Moolenaar NM, Sleegers PJC, Daly AJ (2012) Teaming up: Linking collaboration networks, collective efficacy, and student achievement. Teach Teach Educ 28(2):251-262

Mueller F, Procter S, Buchana D (2000) Teamworking in its context (s): antecedents, nature and dimensions. Human Relat 53(11):1387-1424

Muthén LK, Muthén BO (1998-2012) Mplus user's guide seventh edition. Muthén \& Muthén, Los Angeles

Nguni S, Sleegers P, Denessen E (2006) Transformational and transactional leadership effects on teachers' job satisfaction, organizational commitment, and organizational citizenship behavior in primary schools: The Tanzanian case. Sch Eff Sch Improv 17:145-177

Poortman CL (2007) Workplace learning processes in senior secondary vocational education. (Doctoral dissertation). Retrieved from http://doc.utwente.nl/57877/1/thesis_Poortman.pdf

Preacher KJ, Zyphur MJ, Zhang Z (2010) A general multilevel SEM framework for assessing multilevel mediation. Psychol Methods 15(3):209-233

Putnam RT, Borko H (2000) What do new views of knowledge and thinking have to say about research on teacher learning? Educ Res 29(1):4-15

Richardson V, Placier P (2001) Teacher change. In: Richardson V (ed) Handbook of research on teaching. American Educational Research Association, Washington, pp 905-947

Ritzen H (2004) Zinvolle leerwegen Actieonderzoek naar innovatieve leeromgevingen voor ROC-leerlingen van kwalificatieniveaus 1 en 2 (Meaningful ways to learning: Action research into innovative learning environments for VET college students of qualification levels 1 and 2). Nelissen, Soest

Ross JA, Gray P (2006) Transformational leadership and teacher commitment to organizational values: the mediating effects of collective teacher efficacy. Sch Eff Sch Improv 17(2):179-199

Rowan B (1990) Commitment and control: alternative strategies for the organizational design of schools. In: Cadzen C (ed) Rev Res Educ, 16th edn., pp 353-389

Runhaar PR (2008) Promoting teachers' professional development. University of Twente, Dissertation

Runhaar P, Sanders K, Yang H (2010) Stimulating teachers' reflection and feedback asking: an interplay of self-efficacy, learning goal orientation, and transformational leadership. Teach Teach Educ 26(5):1154-1161

Satorra A, Bentler PM (2001) A scaled difference chi-square test statistic for moment structure analysis. Psychometrika 66(4):507-514

Schippers MC, den Hartog DN, Koopman PL, Wienk JA (2003) Diversity and team outcomes: the moderating effects of outcome interdependence and group longevity and the mediating effect of reflexivity. J Organ Behav 24(6):779-802

Schwarzer R, Hallum S (2008) Perceived teacher self-efficacy as a predictor of job stress and burnout: mediation analyses. Appl Psychol-Int Rev 57:152-171

Schwarzer, R, Schmitz, GS, \& Daytner, GT (1999) The teacher self-efficacy scale. Available at: http://userpage.fu-berlin.de/ $\sim$ health/teacher_se.htm.

Schyns B, Von Collani G (2002) A new self-efficacy scale and its relation to personality constructs and organizational variables. Eur J Work Organ Psy 11:219-241

Scribner JP, Sawyer RK, Watson ST, Myers VL (2007) Teacher teams and distributed leadership: a study of group discourse and collaboration. Educ Admin Quart 43(1):67-100 
Sfard A (1988) On two metaphors for learning and the dangers of choosing just one. Educ Res 27:4-13

Silins HC (1994) The relationship between transformational and transactional leadership and school improvement outcomes. Sch Eff Sch Improv 5:272-298

Silins H, Mulford B, Zarins S (2002) Organisational learning and school change. Educ Admin Quart 38:613-642

Simbula S, Guglielmi D, Schaufeli WB (2011) A three-wave study of job resources, self-efficacy, and work engagement among Italian schoolteachers. Eur J Work Organ Psy 20(3):285-304

Slavin RE (1990) Achievement effects of ability grouping in secondary schools: a best-evidence synthesis. Rev Educ Res 60(3):471-499

Sleegers P, Bolhuis S, Geijsel F (2005) School improvement within a knowledge economy: Fostering professional learning from a multidimensional perspective. In: Bascia N, Cumming A, Datnow A, Leithwood K, Livingstone D (eds) International handbook of educational policy. Kluwer, Dordrecht, pp 527-543

Sleegers PJC, Thoonen EEJ, Oort FJ, Peetsma TTD (2014) Changing classroom practices: the role of school-wide capacity for sustainable improvement. J Educ Admin 52(5):617-652

Smylie MA (1995) New perspectives on teacher leadership. Elem School J 96:3-7

Smylie MA, Lazarus V, Brownlee-Conyers J (1996) Instructional outcomes of school-based participative decision making. Educ Eval Policy An 18:181-198

Somech A, Bogler R (2002) Antecedents and consequences of teacher organizational and professional commitment. Educ Admin Quart 38(4):555-577

Somech A, Drach-Zahavy A (2007) Schools as team-based organizations: a structure-process-outcome approach. Group Dyn-Theor Res 11(4):305-320

Spillane JP, Reiser BJ, Reimer T (2002) Policy implementation and cognition: reframing and refocussing implementation research. Rev Educ Res 72(3):387-431

Spillane JP, Kim CM, Frank KA (2012) Instructional advice and information providing and receiving behavior in elementary schools exploring tie formation as a building block in social capital development. Am Educ Res J 49(6):1112-1145

Staples DS, Webster J (2008) Exploring the effects of trust, task interdependence and virtualness on knowledge sharing in teams. Inf Syst J 18(6):617-640

Stoll L (2009) Capacity building for school improvement or creating capacity for learning? A changing landscape. J Educ Change 10:115-127

Stoll L, Bolam R, McMahon A, Wallace M, Thomas S (2006) Professional learning communities: a review of the literature. J Educ Change 7(4):221-258

Sun J, Leithwood K (2012) Transformational leadership effects on student achievement. Leadersh Policy Sch 11(4):418-451

ten Dam G, Blom S (2006) Learning through participation: the potential of school-based teacher education for developing a professional identity. Teach Teach Educ 22:647-660

Thoonen EEJ, Sleegers PJC, Oort FJ, Peetsma TTD, Geijsel FP (2011) How to improve teaching practices: The role of teacher motivation, organizational factors, and leadership practices. Educ Admin Quart 47(3):496-536

Tjosvold D (1998) Cooperative and competitive goal approaches to conflict: accomplishments and challenges. Appl Psychol-Int Rev 47:285-342

Tjosvold D, Tang MM, West M (2004a) Reflexivity for team innovation in China the contribution of goal interdependence. Group Organ Manag 29(5):540-559

Tjosvold D, Yu ZY, Hui C (2004b) Team learning from mistakes: the contribution of cooperative goals and problemsolving. J Manag Stud 41(7):1223-1245

Truijen K (2012) Teacher teaming: exploring factors that influence effective team functioning in a vocational education context. University of Twente, Dissertation

van der Vegt G, van de Vliert E (2002) Intragroup interdependence and effectiveness: review and proposed directions for theory and practice. J Manage Psychol 17(1):50-67

van der Vegt G, Emans B, van de Vliert E (2000) Team members' affective responses to patterns of intragroup interdependence and job complexity. J Air Waste Manage Assoc 26(4):633-655

van Veelen R, Otten S, Hansen N (2013) A personal touch to diversity: self-anchoring increases minority members' identification in a diverse group. Group Process Interg 16(6):671-683

van Veen $\mathrm{K}$, Sleegers P, van de Ven P (2005) One teacher's identity, emotions and commitment to change: a case study into the cognitive-affective processes of a secondary school teacher in the context of reforms. Teach Teach Educ 21(8):917-934

van Veen K, Zwart R, Meirink J (2012) What makes teacher professional development effective? A literature review. In: Kooy $M$, van Veen $\mathrm{K}$ (eds) Teacher learning that matters: International perspectives. Routledge publishers, London, $\mathrm{pp} \mathrm{3-21}$

van Woerkom M (2003) Critical reflection at work: bridging individual and organisational learning. University of Twente, Dissertation

van Woerkom M (2004) The concept of critical reflection and its implications for human resource development. Adv Develop Hum 6(2):178-192

Wageman R (1995) Interdependence and group effectiveness. Admin Sci Quart 40(1):145-180

Weldon E, Weingart LR (1993) Group goals and group performance. Brit J Soc Psychol 32:3007-3334

Yammarino FJ, Dionne SD, Schriesheim CA, Dansereau F (2008) Authentic leadership and positive organizational behavior: a meso, multi-level perspective. Leadership Quart 19:693-707

Yost, DS (2006) Reflection and self-efficacy: enhancing the retention of qualified teachers from a teacher education perspective. Teach Educ Q Fall:59-76

Yuan KH, Bentler PM (2000) Three likelihood-based methods for mean and covariance structure analysis with non-normal missing data. Sociol Methodol 30:167-202 